\title{
Efektifitas Penggunaan Alat Hydraulic Static Pile Driver (HSPD) pada Pemancangan
}

\author{
${ }^{1}$ Elvira Handayani, ${ }^{2}$ Jauhar Maknun \\ ${ }^{1}$ Program Studi Teknik Sipil UNBARI \\ ${ }^{2}$ Alumni Program Studi Teknik Sipil Unbari \\ elvira.handayani2@yahoo.co.id
}

\begin{abstract}
Abstrak
Pesatnya perkembangan proyek konstruksi di Indonesia berbanding lurus dengan alat - alat yang diciptakan dan dikembangkan untuk membantu dan mempermudah aktivitas dalam pengerjaan proyek konstruksi tersebut. Alat tidak lagi sepenuhnya menggunakan tenaga manusia tetapi manusia hanya menjadi bagian untuk proses pengoperasian alat tersebut. Terbatasnya lahan di kota Jambi menjadi alasan utama dalam pembangunan konstruksi bangunan tinggi. Sehingga, dibutuhkan teknologi khusus agar dapat memudahkan pelaksanaan pembangunan tersebut. Berbicara bangunan bertingkat tidak lepas dari salah satu alat yang dipakai dalam proyek ini, yaitu alat pancang untuk pengerjaan pondasi. Konstruksi pondasi dalam (deep Foundation) mempunyai struktur yang lebih kompleks dibandingkan dengan konstruksi pondasi dangkal (shallow foundation). Oleh karena itu dalam pengerjaan proyek bangunan tinggi, penggunaan jack in pile dirasa sangat tepat. Salah satu kelebihan dari jack in pile adalah gangguan terhadap lingkungan seperti getaran dan kebisingan dapat diminimalkan.Dalam penelitian ini akan membahas salah satu jenis Jack in Pile yaitu type Hydraulic Static Pile Driver (HSPD). Dimana pada kasus ini keefektifitasan penggunaan Hydraulic Static Pile Driver (HSPD) pada proyek Odua Weston akan dibahas menurut literatur serta data - data pendukung yang ada.

Kata kunci :Efektifitas Pemancangan, HSPD, Analisis SWOT
\end{abstract}

\begin{abstract}
The rapid development of construction projects in Indonesia is directly proportional to the tools created and developed to assist and facilitate activities in the work. The tools no longer fully use human power but humans are only a part of the process of operating the tool. Limited land in the city of Jambi became the main reason in the construction of high-rise buildings. Thus, special technology is needed in order to facilitate the implementation of such development. One of the tools used is the tool for foundation work. Deep foundation construction has a more complex structure compared to shallow foundation construction. Therefore, in the construction of high-rise project, the use of jack in pile is considered very appropriate. One of the advantages of jack in pile is environmental disturbance such as vibration and noise can be minimized. In this research will discuss one type of Jack in Pile that is type Hydraulic Static Pile Driver (HSPD). Where in this case the effectiveness of the use of Hydraulic Static Pile Drivers (HSPD) on the Odua Weston project will be discussed according to the literature and supporting data available.
\end{abstract}

Keywords: Effectiveness of Pollution, HSPD, SWOT Analysis

\section{PENDAHULUAN}

Seperti pada halnya proses pembangunan Hotel Odua Weston yang menggunakan mesin Hydraulic Static Pile Driver (HSPD)pada proses pemancangan pondasi tiang pancang Dimana tiang pancang ditekan masuk kedalam sesuai kedalaman yang telah direncanakan dan bukan dipukul kedalam, seperti halnya Drop Hammer karena jika menggunakan Drop Hammer getaran dan kebisingan dari alat 
hammer sangat mengganggu lingkungan. Pembangunan Hotel Odua Weston yang menggunakan alat Hydraulic Static Pile Driver (HSPD) pada proses pemancanganmampu menjadi wajah baru dalam dunia konstruksi di kota Jambi, pasalnya baru beberapa bangunan gedung bertingkat di Jambi yang menggunakan alat tersebut.Dengan mesin yang bervariasi pada tingkat gaya tekanya, mulai dari mesin yang dapat menghasilkan gaya tekan 120 ton, 140 ton, 240 ton, 320 ton, 420 ton, dan 600 ton.Oleh karena itu penulis ingin menyampaikan bagaimana alat Hydraulic Static Pile Driver (HSPD) bekerja diproyek Hotel Odua Weston pada proses pemancangan tiang pancang berdasarkan data - data yang sudah didapatkan.

\section{TINJAUAN PUSTAKA}

\section{Konsep Efektifitas}

Kata efektifitas/efektivitas berasal dari bahasa inggris yaitu effective yang berarti berhasil atau sesuatu yang dilakukan berhasil dengan baik.Kamus ilmiah populer mendefinisikan efektifitas sebagai ketetapan penggunaan, hasil guna atau menunjang tujuan.Dari beberapa pendapat diatas mengenai efektifitas, dapat disimpulkan bahwa efektifitas adalah tingkatan sejauh mana tujuan tercapai dan sejauh mana sasaran masalah dapat diselesaikan.

\section{Ukuran Efektifitas}

Mengukur efektifitas pekerjaan konstruksi bukanlah suatu hal yang sangat sederhana.Karena efektifitas dapat dikaji dari berbagai sudut pandang dan tergantung pada siapa yang menilai serta menginterprestasikannya.Bila dipandang dari sudut pekerjaan konstruksi, maka memberikan pemahaman bahwa efektifitas berarti kualitas, kuantitas, dan waktu pekerjaan.Tingkat efektifitas juga dapat diukur dengan membandingkan antara rencana yang telah ditentukan dengan hasil nyata yang telah diwujudkan.Namun, jika usaha atau hasil pekerjaan dan tindakan yang dilakukan tidak tepat sehingga menyebabkan tujuan tidak tercapai atau sasaran yang diharapkan, maka hal itu dikatakan tidak efektif.

\section{Pondasi Tiang Pancang}

Pondasi tiang pancang dapat dikelompokkan menjadi 3 bagian, large displacement pile, small displacement pile, dan replacement pile.

\section{Pemilihan dan Pengadaan Tiang Pancang}

Pemilihan tiang pancang yang tepat sangat ditentukan faktor - faktor berikut ini:

a. Lokasi dan jenis dari bangunan/struktur.

b. Kondisi tanah setempat.

c. Keawetan.

\section{Karakteristik Tanah}

Data penyelidikan tanah dilakukan oleh PT. Ketira Engineering Consultans pada bulan juni 2013 berupa 10 titik sondir kapasitas 2,5 ton dan boring dalam sebanyak 2 titik kedalaman 30 meter (DB1 dan DB2) serta uji SPT setiap interval 2 meter dan muka ari tanah (GWL) ditemui pada kedalaman -0,50 meter (dari elevasi ekisting soil test). Tes Sondir telah dilaksanakan dengan mempergunakan alat sondir 
berat kapasitas 2,5 ton dilengkapi dengan Adhesion Jacket Cone type Begemann yang dapat mengukur nilai perlawanan konus (Cobe Resistance) dan hambatan lekat (Local Friction) secara langsung dilapangan.

\section{Manajemen Peralatan Konstruksi}

Secara umum, faktor - faktor penting yang merupakan permasalahan pokok dalam manajemen peralatan konstruksi mencakup : pemilihan alat, pengoperasian/penggunaan alat, rencana pemeliharaaan, dan perbaikan alat serta penggantian komponen peralatan.

\section{Pemilihan Alat Pancang}

Pemilihan alat penting untuk dilakukan karena sangat erat kaitannya dengan faktor - faktor yang berpengaruh terhadap tingkat produksi alat. Faktor - faktor yang berpengaruh terhadap tingkat produksi alat tersebut mencakup masalah diantaranya adalah :
a. Tipe dan ukuran.
b. Efisiensi alat.
c. Kondisi tempat kerja serta pengaturannya.
d. Tipe pekerjaan.
e. Pengalaman operator.

\section{Hydraulic Static Pile Driver (HSPD)}

HSPD tidak jauh berbeda dengan Double Acting Steam Hammer dan Deferential Hammer.HSPD ini beroperasi menggunakan fluida hidrolik.Jacking pile dengan menggunakan hydraulic static pile driver adalah sistem pemancangan tiang dengan cara menekan tiang masuk kedalam tanah dengan menggunkan kekuatan sistem hidraulik yang mendapat reaksi pembebanan dari counter weight.Pemancangan dengan menggunakan hydraulic static pile driver tidak menimbulkan getaran dan suara bising. Kelebihannya adalah kita dapat mengetahui besarnya gaya tekan pada tiang dengan membaca langsung pada manometer.

\section{Metode Pelaksanaan dengan Hydraulic Static Pile Driver}

Kerja jacking pile dengan Hydraulic Static Pile Driveradalah sebagai berikut ini :

1. Bersama dengan pemberi Tugas/MK melakukan koordinasi mengenai urutan kerja/prioritas dengan mempertimbangkan urutan penyelesaian pekerjaan yang diminta dan kemampuan akses kerja dengan tujuan utama adalah tercapainya produktivitas yang terbaik.

2. Mengarahkan pile driver ke titik pemancangan dengan mengacu pada urutan yang telah disepakati.

3. Tiang - tiang pancang diletakkan sedekat mungkin dengan lokasi pemancangan. Hal tersebut sangat disarankan agar menghindari terjadinya pemindahan berulang ulang yang dapat menimbulkan resiko tiang rusak.

4. Membuat titik bantu agar membantu kontrol terhadap pergeseran pemancangan.

5. Tiang yang akan dipancang diberi tanda/marking tiap 1 meter atau sesuai yang ditentukan. 
6. Proses pemancangan dimulai dengan memasukkan tiang pancang kedalam grip/clamping box kemudian grip digerakkan naik sampai batas atas dan akan mengikat/memegangi tiang. Tiang siap ditekan.

7. Operator memeriksa HSPD, Unit dalam keadaan rata dengan bantuan "alat nivo"yang terdapat dalam ruangan operator. Kelurusan tiang dapat dikontrol dengan menggunakan waterpass.

8. Pada ruang kontrol dilengkapi dengan manometer oil pressure untuk mengetahui tekanan yang diberikan kepada tiang pancang.

9. Jika grip menekan sampai bagian pangkal lubang mesin, maka penekanan dihentikan dan grip bergerak naik untuk memulai melakukan pemasukan tiang pancang sambungan.

10. Setelah tiang sambungan dijepit erat oleh grip, kemudian mulai dilakukan penekanan mendekati bottom pile, penekanan dihentikan jika tiang sudah bersentuhan. Proses pengelasan sambungan.

11. Jika dalam proses penekanan tiang sudah tidak dapat ditekan lagi dimana terdapat sisa tiang pancang dipermukaan tanah, maka diperlukan pemotongan tiang pancang rata dengan tanah atau sesuai dengan elevasi yang telah direncanakan.

12. Laporan pemancangan harus mendapat persetujuan dari pengawas dari pihak owner atau dari MK.

\section{METODOLOGI PENELITIAN}

\section{Bagan Alir Penelitian}

Metodologi penelitian yang dilakukan dapat digambarkan pada Gambar berikut :

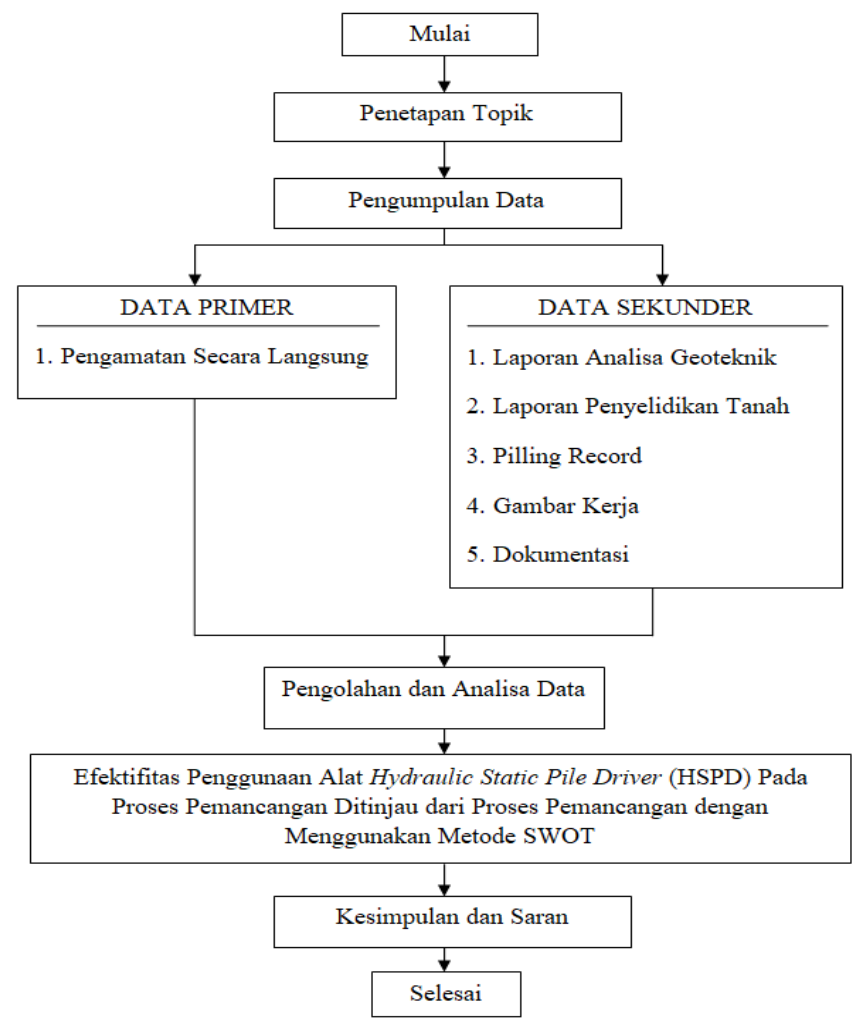

Gambar 1 : Bagan Alir Penelitian 


\section{Analisis Swot}

Analisis efektifitas Hydraulic Static Pile Driver menggunakan metode analisis

SWOT. Dimana analisis SWOT adalah :

$\begin{array}{lll}\mathrm{S} & = & \text { Strength }(\text { Keunggulan) } \\ \mathrm{W} & = & \text { Weakness } \text { (Kelemahan/kekurangan) } \\ \mathrm{O} & = & \text { Opportunity (Peluang) } \\ \mathrm{T} & = & \text { Threat } \text { (Kendala/hambatan) }\end{array}$

\section{Analisis Keunggulan (S)}

Alat Hydraulic Static Pile Driver (HSPD) memiliki keunggulan dilihat dari internal alat tersebut, diantaranya adalah :

1. Tidak menghasilkan suara bising (umumnya menggunakan silent genset) sebagai main power untuk aktivitas mesin Hydraulic Static Pile Driver sehingga tidak menghasilkan polusi asap yang berlebih.

2. Tidak menimbulkan getaran disekeliling, sehingga aman buat bangunan disekitarnya (minim retak structural pada bangunan disekitarnya).

3. Tidak diperlukan loading test beban aksial, karena mesin Hydraulic Jack-in dilengkapi dengan pressure gauge (MPa) sehingga beban aksial aktual dapat diketahui dari pembacaan nilai (MPa) pada pressure gauge di instrument mesin.

4. Alat Hydraulic Static Pile Driver bisa memancang pile dekat dengan dinding pembatas.

Analisis Kelemahan (W)

Alat Hydraulic Static Pile Driver (HSPD) memiliki kelemahan/ kekurangan dilihat dari internal alat tersebut, diantaranya adalah :

1. Jika menggunakan alat Hydraulic Static Pile Driver alat lambat untuk berpindah dari satu titik ke titik pemancangan yang lain.

2. Pada saat mobilisasi alat ke lokasi proyek alat Hydraulic Static Pile Driversangat tergantung terhadap ketersediaan mobil pengangkut.

3. Investasi mahal.

4. Alat Hydraulic Static Pile Driver sangat berat.

5. Terlalu banyak bagian - bagian dari alat Hydraulic Static Pile Driver tersebut yang harus dibongkar pasang baik pengoperasian alat ataupun saat mau mobilisasi alat.

\section{Analisis Peluang (O)}

Alat Hydraulic Static Pile Driver (HSPD) memiliki peluang untuk terus dikembangkan di masa yang akan datang, diantaranya adalah :

1. Dikembangkan dari segi efektifitas alat.

2. Dikembangkan dari segi mobilisasi alat.

3. Dikembangkan dari segi system manuver alat, dan lainnya 
Analisis Kendala/Hambatan (T)

Alat Hydraulic Static Pile Driver (HSPD) memiliki kendala/hambatan dilihat dari sisi eksternal alat tersebut karena kondisi lapangan, diantara kendala/hambatan tersebut adalah sebagai berikut:

1. Lokasi proyek yang berada dilokasi yang kecil membuat alat Hydraulic Static Pile Driver agak sulit bermanuver, hal ini disebabkan alat Hydraulic Static Pile Drivermemiliki body yang besar dan berat yang sangat besar juga sehingga alat ini cukup makan tempat.

2. Alat Hydraulic Static Pile Drivertidak bisa bekerja di kontur tanah yang tidak rata/datar. Jika kontur tanah tidak rata/datar maka tanah harus diratakan.

3. Alat Hydraulic Static Pile Drivertidak bisa bekerja di elevasi tanah yang lebih tinggi atau lebih rendah dari alat tersebut karena alat Hydraulic Static Pile Driver bekerja di tanah yang datar/rata, solusinya adalah menggunakan alat lain seperti bor pile.

4. Alat Hydraulic Static Pile Drivertidak bisa digunakan di tanah yang lunak karena alat Hydraulic Static Pile Driver memiliki berat beban yang cukup besar.

\section{Produktivitas Alat HSPD Berdasarkan Laporan Pilling Record}

Data produktivitas alat dari laporan pilling record digunakan untuk mendapatkan tingkat efektifitas alat Hydraulic Static Pile Driver yang bekerja di proyek hotel Odua Weston Jambi.

\section{Profil Alat}

$\begin{array}{ll}\text { Nama Alat } & : \text { Hydraulic Static Pile Driver } \\ \text { Type } & : \text { ZYC600B-B } \\ \text { Kapasitas Angkut } & : 600.000 \mathrm{Kg} \\ \text { Pilling Speed } & : \text { Fast }: 4.2 \mathrm{~m} / \mathrm{min} \\ & \text { Low }: 1.02 \mathrm{~m} / \mathrm{min} \\ \text { Pace } & : \text { Longitudinal }: 3.6 \mathrm{~m} \\ & \text { Horizontal : } 0.7 \mathrm{~m} \\ \text { Max Square Pile } & : 550 \times 550 \mathrm{~mm} \\ \text { Max Circle Pile } & : 600 \mathrm{~mm} \\ \text { Lifting Weight } & : 16 \mathrm{Ton} \\ \text { Lifting Pile's Length } & : 15 \mathrm{~m} \\ \text { Rice Stroke } & : 1.2 \mathrm{~m} \\ \text { Total Weight } & : 600 \mathrm{Ton}\end{array}$

\section{Profil Tiang Pancang}

Tiang Pancang: Spun Pile $\varnothing 600 \mathrm{~mm}$

Spun Pile $\varnothing 500 \mathrm{~mm}$

Mutu Beton : K-500

\section{Kondisi Tanah Dasar}

Berdasarkan data - data hasil penyelidikan tanah dilapangan dan laboratorium (lihat lampiran), secara umum kondisi tanah dasar (sub surface soil condition) untuk proyek hotel Odua Weston Jambi, dapat dijelaskan sebagai berikut : 
Tabel 1 : Hasil Penyelidikan Tanah

\begin{tabular}{ll}
\hline Kedalaman (m) & \multicolumn{1}{c}{ Deskripsi Tanah } \\
\hline $0,00-7,00$ & Berupa lanau lempung kepasiran (sandy clayey SILT) \\
$7,00-14,50$ & Merupakan jenis lapisan pasir kelanauan (silty SAND) \\
$14,50-20,00$ & Berupa jenis lanau lempung kepasiran (sandy clayey SILT) \\
$20,00-30,00$ & Merupakan jenis lanau kelempungan (clayey silt) \\
\hline
\end{tabular}

Sumber : PT. Ketira Engineering Consultants (2013)

\section{Pilling Record}

Pekerjaan pemancangan tiang pancang dikerjakan oleh PT. Tribangun Pilar Persada pada bulan maret hingga april 2014. Pekerjaan pemacangan menggunakan alat Hydraulic Static Pile Driver. Pada perhitungan produktivitas alat Hydraulic Static Pile Driverkali ini penulis mengambil sampel data dari piling record tertanggal 22 maret 2014 untuk mewakili sampel data yang diambil dari piling record.

Diambilnya data dari tanggal tersebut karena pertanggal tersebutlah aktivitas alat Hydraulic Static Pile Driver memiliki jumlah yang cukup banyak dan rata - rata kedalamannya 1 titik pancang adalah 30 meter.

Tabel 2. Piling Record 22 Maret 2014 HSPD $600 \mathrm{~T}$

\begin{tabular}{|c|c|c|c|c|c|c|}
\hline \multirow[b]{2}{*}{ Tanggal } & \multirow{2}{*}{$\begin{array}{l}\text { No } \\
\text { Titik }\end{array}$} & \multirow{2}{*}{$\begin{array}{c}\text { Diameter } \\
\text { Tiang } \\
(\mathrm{cm})\end{array}$} & \multicolumn{3}{|c|}{ Panjang Tiang Diangkat } & \multirow{2}{*}{$\begin{array}{c}\text { Jumlah } \\
\text { (M) }\end{array}$} \\
\hline & & & $(\mathrm{M})$ & $(\mathrm{M})$ & $(\mathrm{M})$ & \\
\hline 22-Mar-14 & $\mathrm{I} 6 / 3$ & 60 & 12 & 6 & 12 & 30 \\
\hline 22-Mar-14 & I6/4 & 60 & 12 & 6 & 12 & 30 \\
\hline 22-Mar-14 & $\mathrm{I} 6 / 5$ & 60 & 12 & 6 & 12 & 30 \\
\hline 22-Mar-14 & $\mathrm{I} 6 / 6$ & 60 & 12 & 6 & 12 & 30 \\
\hline 22-Mar-14 & $\mathrm{I} 5 / 1$ & 60 & 12 & 6 & 12 & 30 \\
\hline 22-Mar-14 & $\mathrm{I} 5 / 2$ & 60 & 12 & 6 & 12 & 30 \\
\hline 22-Mar-14 & $\mathrm{I} 5 / 3$ & 60 & 12 & 6 & 12 & 30 \\
\hline 22-Mar-14 & $\mathrm{I} 5 / 4$ & 60 & 12 & 6 & 12 & 30 \\
\hline
\end{tabular}

Sumber : PT. Tribangun Pilar Persada (2014)

Pada tanggal 22 maret 2014 alat hydraulic static Pile driver mampu menyelesaikan 2 titik pancang (I5 dan I6) dengan kedalaman masing - masing 30 meter.

Diketahui :

1 hari pemancangan $=24$ pile, dengan rincian :

$=16$ pile dengan ukuran panjang 12 meter

$=8$ pile dengan ukuran panjang 6 meter

Jam Kerja Produktif $=$ Jam 08:00 WIB $-12: 00$ WIB $=4$ Jam (jam efektif kerja)

$=$ Jam 12:00 WIB $-13: 00 \mathrm{WIB}=1 \mathrm{Jam}$ (istirahat)

$=$ Jam 13:00 WIB $-17: 00 \mathrm{WIB}=4$ Jam (jam efektif kerja)

Jadi, jam efektif kerja 1 harinya adalah $=8$ Jam

Produkivitas alat hydraulic static pile driver (pile/jam)

$\frac{24 \text { Pile }}{8 \text { Jam }}=3$ pile/jam

Dengan rincian pekerjaan 3 pile/jam, adalah sebagai berikut :

Efektifitas Penggunaan Alat Hydraulic Static Pile Driver (HSPD) pada Pemancangan 
1. Lifting pile

2. Clamping dan piling

3. Welding

\section{SIMPULAN}

Berdasarkan hasil pembahasan yang menggunkan metode analisis SWOT maka dapat disimpulkan bahwa :

1. Alat Hydraulic Static Pile Driver sangat efektif digunakan pada proyek pembangunan gedung yang berada ditengah kota/keramaian karena tidak menimbulkan kebisingan dan getaran terhadap bangunan disekitarnya. Namun berbanding terbalik dengan alat Drop Hammer, alat ini menimbulkan kebisingan, polusi udara, dan dapat membuat bangunan disekitarnya rusak dikarenakan aktifitas alat ini.

2. Alat hydraulic static pile driver per-harinya mampu memancang pile sebanyak 24 piles.

\section{Saran}

Perlu adanya upgrade alat Hydraulic Static Pile Driver yang mampu bergerak secara fleksibel, cepat, dan efisien untuk menunjang tingkat produktivitas yang lebih baik.

\section{DAFTAR PUSTAKA}

(Lokbin) Rawa Buana. 23 Februari 2017. http://digilib.mercubuana.ac.id/

Alat Hydraulic Static Pile Driver.8 Agustus 2017.

Andi Tenrisukki Tenriajeng. 2003. Pemindahan Tanah Mekanis, UniversitasGunadarma. Jakarta.

Feng Sara. Komponen Alat Hydraulic Static Pile Driver. 8 Agustus 2017

http://ilmumanajemenindustri.com/pengertian-contoh-analisis-swot/

http://www.okorder.com/p/cmax360b-ii-series-hydraulic-static-pile-driver-forsale_938364.html

Indonesia. Jakarta.

indonesia.alibaba.com/product-detail/zyc-600-static-pile-driver-silent-pilingfoundation-machinery-747597033.html

Komponen Dasar Analisis SWOT. 28 Agustus 2017.

Limanto Sentosa. 2009. Analisis Produktivitas Pemancangan Tiang Pancang Pada Bangunan Tinggi Apartement, Universitas Kristen Petra. Surabaya.

Metode Kerja Alat Hydraulic Static Pile Driver Pada Proyek Apartement Victoria Square Tower B. 23 Februari 2017. http://digilib.mercubuana.ac.id/

Metode Kerja Alat Hydraulic Static Pile Driver Pada Proyek Rumah Susun Soemardikatmojo igig. 2003. Alat - Alat Berat, Universitas Indonesia, Jakarta.

Wilopo Djoko. 2009. Metode Konstruksi dan Alat - Alat Berat, Universitas www.alibaba.com/product-detail/indonesia-buyer-recommend-usedpiledriver_60476626427.html

Yuan Ivy.Spesification of Hydraulic Static Pile Driver.8 Agustus 2017. 